Article

\title{
Rapid Generation of Monoclonal Antibodies from Single B Cells by Ecobody Technology
}

\author{
Teruyo Ojima-Kato ${ }^{1,2, *} \mathbb{B}$, Shiomi Morishita ${ }^{2,+}$, Yoshino Uchida ${ }^{2,{ }^{\dagger}}$, Satomi Nagai ${ }^{1}$, \\ Takaaki Kojima ${ }^{2}$ and Hideo Nakano ${ }^{1,2}$ \\ 1 iBody Inc., Furo-cho 1, Chikusa-ku, Nagoya 464-0814, Japan; nagai.satomi@molbiotech-nagoya.org (S.N.); \\ hnakano@agr.nagoya-u.ac.jp (H.N.) \\ 2 Graduate School of Bioagricultural Sciences, Nagoya University, Furo-cho, Chikusa-ku, \\ Nagoya 464-8601, Japan; morishita.shiomi@molbiotech-nagoya.org (S.M.); \\ uchida.yoshino@molbiotech-nagoya.org (Y.U.); kojimat@nuagr1.agr.nagoya-u.ac.jp (T.K.) \\ * Correspondence: kato.teruyo@ibody.co.jp or teruyo.ojima@gmail.com; Tel.: +81-52-753-8654 \\ + There authors contributed equally to this work.
}

Received: 25 September 2018; Accepted: 31 October 2018; Published: 7 November 2018

check for updates

\begin{abstract}
Single B cell sampling following to direct gene amplification and transient expression in animal cells has been recognized as powerful monoclonal antibodies (mAbs) screening strategies. Here we report Ecobody technology which allows mAbs screening from single B cells in two days This technology uses Escherichia coli cell-free protein synthesis (CFPS) for mAb expression. In the CFPS step, we employed our original techniques: (1) 'Zipbody' as a modified Fab (fragment of antigen binding) format, in which the active Fab formation is facilitated by adhesive leucine zipper peptides fused at the C-termini of the light and heavy chains; and (2) an N-terminal SKIK peptide tag that can markedly increase protein production. By the Ecobody technology, we demonstrated rapid screening of antigen specific mAbs from immunized rabbits and Epstein-Barr Virus infected human B cells. We further obtained rabbit $\mathrm{mAbs}$ in $E$. coli expression system yielding to $8.5 \mathrm{mg}$ of purified proteins from $1 \mathrm{~L}$ bacterial culture.
\end{abstract}

Keywords: single B cell technology; rabbit antibodies; human antibodies

\section{Introduction}

Monoclonal antibodies (mAbs) have become essential agents for research, diagnostic and therapeutic areas.

Single B cell screening technologies, which can rapidly generate mAbs from sampled single B cells from immunized animals, have been proven to be powerful techniques to obtain the natural antibody repertoire [1-5]. Usually in these methods, recombinant production of the mAbs is performed using animal cells like CHO and HEK293, resulting in a rate-limitation of the screening process, because transfection and expression in animal cells requires at least 3-5 days. In contrast, cell-free protein synthesis (CFPS) offers an alternative expression system that avoids many of the problems of conventional cell-based expression technologies [6,7]. CFPS has big advantages over in vivo methods for high-throughput recombinant protein production without requiring time-consuming gene-cloning, transformation, or cultivation [8].

Taking advantage of CFPS systems, we developed a rapid mAb screening system named "Single-Cell Reverse Transcription-PCR linked in vitro Expression (SICREX)", which utilizes Escherichia coli extract-based CFPS systems to produce fragments of antigen binding (Fab) derived from single B cells [9-11]. Using this method, proteins can be rapidly synthesized just by mixing the E. coli cell-extract with PCR-amplified DNA templates, amino acids, nucleotides, T7 RNA polymerase and an 
energy source. However, practically available $\mathrm{mAb}$ screening was challenging due to the following technical problems. Firstly, active Fabs were sometimes not formed in the CFPS because of incorrect folding and assembling of heavy chain (Hc) and light chains (Lc). In particular, active Fabs were not produced at all in the case of rabbit mAb clones, probably because of the presence of too many Cys residues involved in disulfide bond formation [11,12]. Therefore, reconstruction of single chain $\mathrm{Fv}$ $(\mathrm{scFv})$ genes was required for enzyme-linked immunosorbent assay (ELISA) evaluation. Secondly, the protein production levels significantly depend on the clones or genes and it was difficult to obtain enough mAb proteins in CFPS for ELISA evaluation. In some cases, the amount of Hc and Lc gene templates included in the CFPS should be optimized [13,14]. To overcome such limitations, we have recently developed a modified Fab format named 'Zipbody' that contains adhesive short peptides leucine zippers (LZ) at the C-terminus of the $\mathrm{Hc}$ and Lc, respectively. We found that the fusion of the $\mathrm{LZ}$ to the Fab could enhance correct pairing of the Hc and Lc, leading to the formation of active Fab in both Escherichia coli CFPS and living cell expression systems [15]. Furthermore, we found that the protein production levels can be markedly improved by just inserting 12 nucleotides next to the start codon [16]. This sequence encodes a short peptide Ser-Lys-Ile-Lys (SKIK).

Together with Zipbody and the SKIK peptide tag technologies, for improvement of Fab formation and protein production in CFPS, we have developed an improved SICREX system renewed as 'Ecobody technology' [17]. Here, we demonstrate a 2-day protocol to complete screening of antigen-specific $m$ Abs from single B cells of rabbits and Epstein-Barr Virus (EBV) infected human B cells. We further describe active Zipbody production in E. coli cytoplasmic expression system followed by refolding of inclusion bodies.

Ecobody technology will be beneficial to the field of $\mathrm{mAb}$ research and development as a high-throughput and low-cost mAb screening method.

\section{Materials and Methods}

\subsection{Overview of Ecobody Technology}

The scheme of Ecobody technology is illustrated in Figure 1. The details are designed as below; (i) Collect blood samples from immunized animals or human donors. (ii) Collect lymphocytes by density gradient centrifugation. (iii) Select target $B$ cells by such as fluorescent reagents and magnetic beads. (iv) Separate single cells per wells by fluorescence-activated cell sorting, limiting dilution method, or some other devices like micromanipulator. (v) RT-PCR from single B cells to prepare Zipbody genes fused with $\mathrm{N}$-terminal SKIK peptide tag. This step includes cell direct reverse transcription with $\mathrm{mAb}$ genes specific primers (15 min), first PCR to amplify Hc and Lc (1 h), second PCR to connect the required DNA tails for the following DNA assembly $(1 \mathrm{~h})$, Gibson assemble with the vector which contains sequences of T7 promoter, N-terminal SKIK peptide tag, Zipbody construct, His tag or HA tag, and T7 terminator (15 min), and final PCR to prepare Hc and Lc DNA fragments for expression. (vi) E. coli based cell-free protein synthesis ( $1.5 \mathrm{~h}$ ). (vii) mAbs evaluation by ELISA ( $3 \mathrm{~h}$ ). 


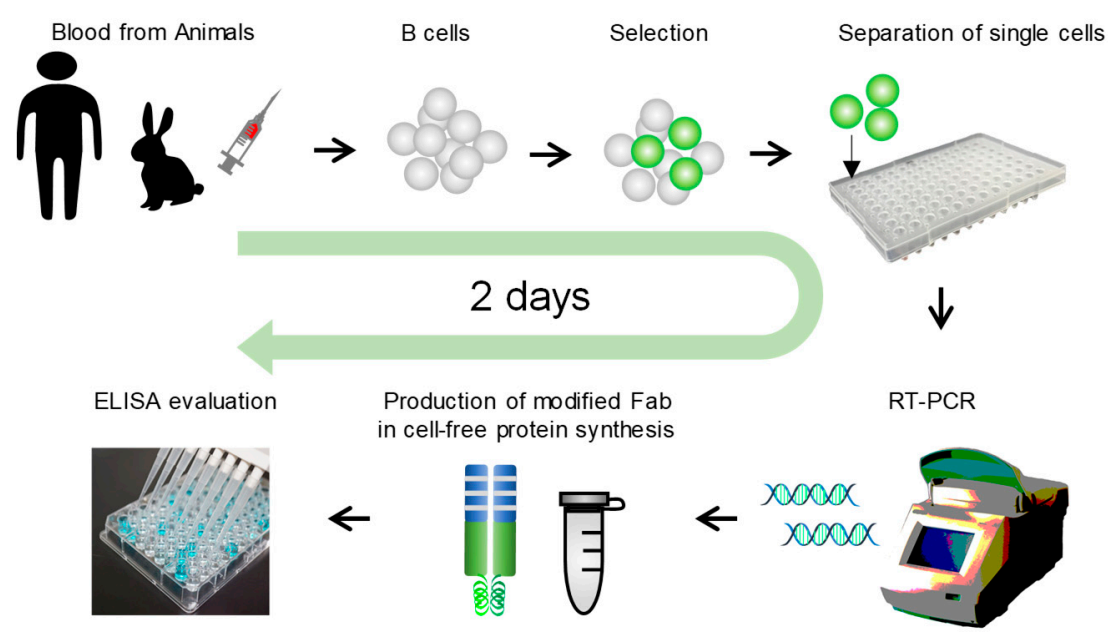

Figure 1. Scheme of the Ecobody technology. The whole process is seamlessly carried out in vitro. The modified Fab (fragment of antigen binding) format 'Zipbody' and 'N-terminal SKIK peptide tag' are the key techniques to obtain enough and active monoclonal antibodies (mAb) proteins in Escherichia coli cell-free protein synthesis.

\subsection{Preparation of Antigens and Immunization of Rabbits}

Three types of antigens, bacteria Vibrio parahaemolyticus NBRC 12711, E. coli O26 GTC14538 (verotoxin-1 producing strain), and non-toxic verotoxin 2 (VT2) were used as antigens for immunization of rabbits. Bacteria were obtained from the Biological Resource Center at the National Institute of Technology and Evaluation (NITE, Kisarazu, Japan) and the National BioResource Project GTC Collection (Gifu, Japan), cultured in Luria-Bertani (LB) medium at $37^{\circ} \mathrm{C}$ overnight, and inactivated by incubating at $80{ }^{\circ} \mathrm{C}$ for $30 \mathrm{~min}$ in phosphate-buffered saline (PBS) containing $0.25 \%$ formalin. They were stored at $-20^{\circ} \mathrm{C}$. Nontoxic VT2 (E167Q mutant) expression vector was prepared by PCR from VT2 producing E. coli O157 GTC 14535 strain with the primers AAGAAGGAGATATACATATGAAGTGTATATTATTTAAATGGGTACTG (forward) and TGGTGGTGGTGGTGCTCGAGGTCATTATTAAACTGCACTTCAGCAAAT (reverse) using KOD FX polymerase (Toyobo, Osaka, Japan). After NdeI and XhoI treated PCR product and pET22b vector were ligated, inverse PCR introducing E167Q mutation into VT2a subunit was performed with primers ACAGCACAAGCCTTACGCTTCAG and TAAGGCTTGTGCTGTGACAGTG using KOD Plus polymerase (Toyobo). The His-tagged nontoxic VT2 was expressed in BL21 (DE3) pLysS and purified using Ni-Sepharose 6 Fast Flow resin (GE healthcare, Little Chalfont, UK) and HT-Hydroxy apatite (Bio-rad, Hercules, CA, USA) as described by He et al. [18]. The two bands of subunit VT2a E167Q $(36 \mathrm{kDa})$ and $2 \mathrm{~b}-\mathrm{His}$ tag $(11 \mathrm{kDa})$ were confirmed by CBB staining after SDS-PAGE. New Zealand White rabbits (2-3 weeks) were immunized with $10^{8}$ dead bacterial cells or $0.2 \mathrm{mg} / \mathrm{mL}$ of nontoxic VT2 supplemented with $2.5 \mathrm{~mL}$ of complete Freund's adjuvant by hypodermic injection. The second and third boosters were given after intervals of 2 weeks and 10 days, respectively. A few $\mathrm{mL}$ of blood samples was collected 2 days after the final booster. This study was approved by the Committee of Animal Experiments of the Graduate School of Bioagricultural Sciences, Nagoya University (permit number 2015022611) and performed according to the Regulations on Animal Experiments in Nagoya University.

\subsection{Preparation of EBV Infected Human Cells}

The EBV infected cell line HEV0011, provided by the RIKEN BRC (Tsukuba, Japan) through the National Bio-Resource Project of the MEXT/AMED [19], was once cultured in RPMI1640 medium with $20 \%$ FBS in T75 flask at $37^{\circ} \mathrm{C}$ with $5 \% \mathrm{CO}_{2}$. The proliferated cells $\left(10^{6}\right.$ cells/tube) were stored in $1 \mathrm{~mL}$ of the same medium supplemented with $10 \%$ dimethyl sulfoxide in liquid nitrogen. 


\subsection{Selection of B Cells}

\subsubsection{Selection of Rabbit B Cells Binding to Bacterial Cells}

After a few $\mathrm{mL}$ of blood samples were collected from the immunized rabbits, lymphocytes were separated by a previously reported protocol using density-gradient centrifugation [11]. To select matured B cells, $10^{6}$ cells/mL-PBS were stained with $1 \mu \mathrm{M}$ ER-Tracker ${ }^{\mathrm{TM}}$ Green (BODIPY ${ }^{\circledR}$ FL Glibenclamide, Life Technologies, Foster City, CA, USA) at room temperature for $5 \mathrm{~min}$ then centrifuged at $1000 \times g$ for $2 \mathrm{~min}$ as described by Kurosawa et al. [2]. The cells with higher fluorescence intensity were then sorted by fluorescence activated cell sorting (FACS, JSAN; Bay Bioscience, Kobe, Japan). Next, the sorted cells were selected with antigen-coated magnetic beads as described previously [11]. In brief, biotinylated dead bacterial cells conjugated with DynaBeads M-280 Streptavidin (SA beads, Life Technologies) were prepared and these beads were used to concentrate B cells that bound to the antigens after removing cells non-specifically bound to SA-beads and E. coli DH5alpha-coated beads. After that, the remaining B cells were separated into each well ( 1 cell $/ 10 \mu \mathrm{L}-\mathrm{PBS})$ of $0.2 \mathrm{~mm}$ glass-bottomed 384-well imaging plates (Corning, Corning, NY, USA) and the bead-B cell complexes in each well were confirmed under a phase-contrast inverted microscope (CKX53; Olympus, Tokyo, Japan). Bürker-Türk plates were used for cell counting.

\subsubsection{Selection of Rabbit B Cells Producing mAbs to Nontoxic VT2}

The lymphocytes fraction separated by the same method as above was stained with ER-tracker and HiLyte Fluor 647 labeled nontoxic VT2 which was prepared by HiLyte Fluor ${ }^{\mathrm{TM}} 647$ Labeling Kit- $\mathrm{NH}_{2}$ (Dojindo Laboratories, Kumamoto, Japan). After replacing the solution with new PBS, the cells with double positive signals were separated into a 96 well PCR plate containing $10 \mu \mathrm{L}$ of RT reaction mixture/well by the single cell sorting mode of cell sorter SH800 (SONY, Tokyo, Japan).

\subsubsection{Selection of Influenza Vaccine Reactive EBV Infected Human Cells}

The stored HEV0011 cells were sub-cultured in a T25 culture flask overnight. Then, the cells were incubated with $11 \mu \mathrm{L} / \mathrm{mL}$ of HiLyte Fluor 647 labeled anti-Human IgG (Fc specific) antibody produced in goat (Merck, Kenilworth, NJ, USA) in PBS at $20^{\circ} \mathrm{C}$ for $20 \mathrm{~min}$. The cells were centrifuged $(1000 \times g$ for $3 \mathrm{~min})$ to replace the solution with $1 \mathrm{~mL}$ new PBS. The cells with higher HiLyte Fluor 647 fluorescence were collected by FACS (JSAN Bay Bioscience, Kobe, Japan). Next, the sorted cells $\left(10^{3}\right.$ cells $/ 100 \mu \mathrm{L}$ PBS) were mixed with $5 \mu \mathrm{L}$ of magnetic beads coated with $E$. coli DH5alpha $\left(6 \times 10^{5}\right.$ beads $/ \mu \mathrm{L}$ PBS $)$ and incubated at room temperature for $10 \mathrm{~min}$. After removing beads fraction with a magnet stand, cells in the supernatant were mixed with $5 \mu \mathrm{L}$ of magnetic beads coated with influenza vaccine (Biken HA, manufactured in 2017, containing A/Singapore/GP1908/2015 (H1N1) pdm09, A/Hong Kong/4801/2014 (H3N2), B/Phuket/3073/2013 (Yamagata strain), and B/Texas $/ 2 / 2013$ (Victoria strain) $)\left(6 \times 10^{5}\right.$ beads $/ \mu$ L PBS $)$ and incubated as well. The cells bound to the beads were collected, diluted to 1 cell $/ 10 \mu \mathrm{L}$ PBS, and separated into a 384 well glass plate to be 1 cell/well.

\subsection{RT-PCR}

Reverse transcription from the single cell, 1st PCR, and 2nd PCR were serially carried out as described previously [17]. In the case of human mAbs, variable regions of kappa and lambda types of Lc, and gamma and mu of Hc were separately amplified. The 2nd PCR products were assembled with the linearized pRSET-based cloning vectors containing T7 promoter, $\mathrm{N}$-terminal SKIK peptide tag, constant regions of Lc or Hc, LZ (LZA or LZB), His or HA tag, and T7 terminator. 


\subsection{Cell-Free Protein Synthesis (CFPS)}

To express SKIK-fused Zipbody, the DNA templates of Hc and Lc were amplified from the above assembled vectors with primers annealed to upstream of the T7 promoter and downstream of the T7 terminator. E. coli-based PURE system (GeneFrontier, Kashiwa, Japan) with oxidized glutathione (GSSG) and DsbC were used as recommended by the manufacturer. Proteins were expressed on a $10-\mu \mathrm{L}$ scale containing $0.5 \mu \mathrm{L}$ PCR product or $20 \mathrm{ng}$ purified DNA fragments (each of Hc and Lc) as the template, at $37^{\circ} \mathrm{C}$ for $90 \mathrm{~min}$. FluoroTect ${ }^{\mathrm{TM}} \mathrm{Green}_{\text {Lys }}$ in vitro Translation Labeling System (Promega, Madison, WI, USA) was included to confirm protein synthesis in subsequent SDS-PAGE analysis.

\subsection{ELISA}

Unless otherwise stated, mAbs produced in CFPS or E. coli were analyzed by ELISA using our standard protocol described previously. In brief, $50 \mu \mathrm{L}$ of dead bacterial cells (OD600 $\mathrm{nm}=0.1$ ) or $10 \mu \mathrm{g} / \mathrm{mL}$ protein antigens (nontoxic VT2 or influenza vaccine), $0.4 \%$ Bovine Serum Albumin (BSA) in PBS as negative control were coated on the MaxiSorp plate (Thermo) overnight, and we followed the standard ELISA protocol using Zipbody as the primary antibody, and anti-rabbit $\operatorname{Ig}(\mathrm{G}+\mathrm{M})-\mathrm{HRP}$ conjugate (Southern Biotech, Birmingham, AL, USA), anti-His tag-HRP conjugate as the secondary antibody, or anti human $\operatorname{IgG}(\mathrm{H}+\mathrm{L})$ polyclonal antibody-HRP conjugate produced in goat (GeneTex, Irvine, CA, USA). Can Get Signal Immunoreaction Enhancer Solution 2 (Toyobo) was used for dilution of the secondary antibody.

\section{8. $m$ Ab Production in E. coli}

To produce the Zipbody with an SKIK tag, Hc and Lc were coexpressed in E. coli Shuffle T7 Express (New England Biolabs, Ipswich, MA, USA) as the host, grown in $50 \mathrm{~mL}$ LB medium supplemented with $100 \mathrm{\mu g} / \mathrm{mL}$ ampicillin with $1 \mathrm{mM}$ IPTG induction at $16^{\circ} \mathrm{C}$ for $24 \mathrm{~h}$, as described in our previous study [17]. The inclusion bodies were refolded by the stepwise dialysis method using guanidinium hydrochloride [20]. In the case of anti-nontoxic VT2 mAb clone, Hc and Lc genes independently cloned into pET22b were separately expressed in E. coli BL21star (DE3) hovering plasmid pSJS1240 in the same medium with $100 \mu \mathrm{g} / \mathrm{mL}$ spectinomycin at $37^{\circ} \mathrm{C}$ for $4.5 \mathrm{~h}$. The amount of inclusion bodies of $\mathrm{Hc}$ and Lc was equalized and refolded together in the single dialysis tube. The KD values were measured by Bio-layer interferometry method.

\section{Results}

\subsection{Rabbit mAbs Screening}

We followed the workflow of Ecobody technology shown in Figure 1 to develop mAbs that bind to V. parahaemolyticus, E. coli O26, and nontoxic VT2. The details are described in the following sections.

\subsubsection{V. parahaemolyticus}

First, $6.8 \times 10^{6}$ lymphocytes were collected from a few milliliters of blood of a rabbit immunized with dead $V$. parahaemolyticus. The cells, about 30\% $\left(2.0 \times 10^{4}\right.$ cells $)$, showing higher fluorescence stained with ER tracker were collected by FACS. Subsequently, approximately 500 cells bound to magnetic beads coated with dead V. parahaemolyticus were separated by magnet, of which 19 were used for single-cell RT-PCR. From them, seven pairs of Lc and Hc genes were obtained (three IgM and four IgG clones, named $3 \mathrm{G}, 5 \mathrm{M}, 7 \mathrm{M}, 20 \mathrm{G}, 22 \mathrm{G}, 30 \mathrm{M}$, and $36 \mathrm{G}$ ). They were expressed in CFPS and evaluated by ELISA. All the clones, expressed as the Zipbody with the N-terminal SKIK tag, had higher binding activity toward $V$. parahaemolyticus than toward the other tested antigens (Figure 2a). Clone $22 \mathrm{G}$ had the highest ELISA signal and low cross-reactivity. 


\subsubsection{E. coli $\mathrm{O} 26$}

The mAb screening process for anti-E. coli $\mathrm{O} 26$ was almost the same as that described above, except for an additional step to remove B cells cross-reacting with E. coli O111 before selection with E. coli O26-coated beads. From $3.0 \times 10^{6}$ lymphocytes, $5.4 \times 10^{4}$ cells were sorted by FACS and finally 750 cells were collected with $E$. coli $\mathrm{O} 26$-coated beads. From these, 22 cells were subjected to single-cell PCR and 10 pairs of Hc and Lc genes (clone names 1 M, 2 G, 3 M, 5 G, 6G, 9 G, 10 G, 12 G, 14 G, and $15 \mathrm{G}$ ) were obtained (data not shown). As the DNA of $3 \mathrm{M}$ and $5 \mathrm{G}$ were not amplified by PCR following Gibson assembly, in total, eight clones were expressed in CFPS and evaluated by ELISA, and each showed a higher signal with E. coli O26 than with BSA (negative control) (Figure 2b).

\subsubsection{Nontoxic VT2}

For nontoxic VT2 mAbs, $6.2 \times 10^{5}$ cells were used and 165 cells $(0.26 \%)$ were selected as ER tracker positive and antigen specific ones. From these, 47 cells were sorted into PCR tubes with single cell sorting mode. Of which, 8 pairs of Hc and Lc genes (clone names $4 \mathrm{M}, 5 \mathrm{M}, 12 \mathrm{M}, 14 \mathrm{G}, 25 \mathrm{M}$, $28 \mathrm{M}, 38 \mathrm{M}$, and $46 \mathrm{M}$ ) were finally obtained and subjected to CFPS and ELISA. All clones showed high ELISA signals toward antigen (Figure 2c).

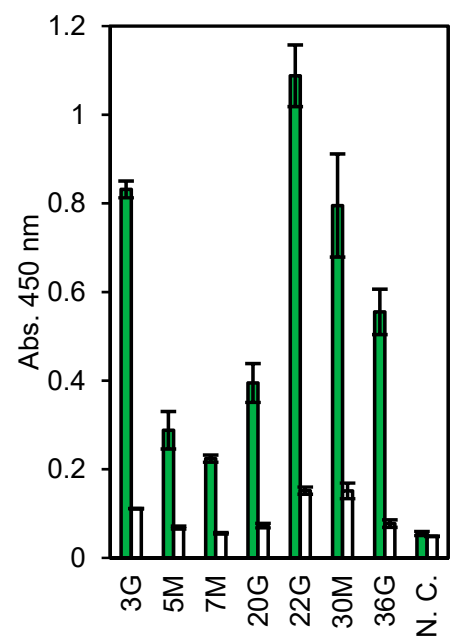

(a)

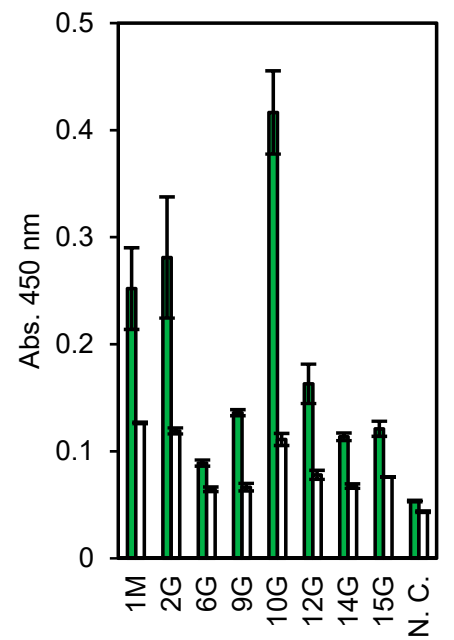

(b)

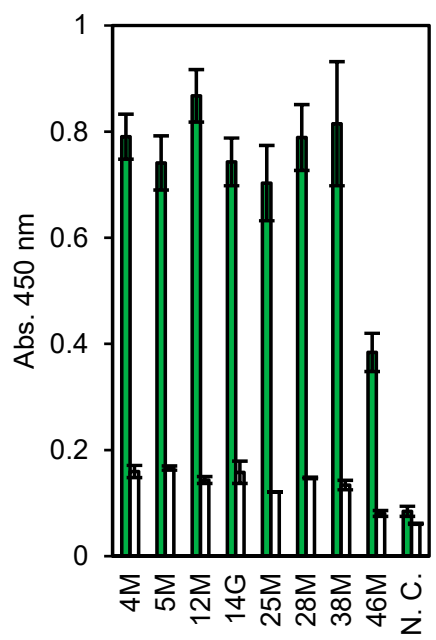

(c)

Figure 2. Enzyme-linked immunosorbent assay (ELISA) results of the cell-free products. Antigens are (a) Vibrio parahaemolyticus. (b) Escherichia coli O26, and (c) nontoxic VT2. Green: Antigen, White: Bovine serum albumin (BSA). N. C. means no DNA templates in the cell-free protein synthesis (CFPS) reaction. Error bars indicate standard deviations.

\subsection{Expression in E. coli}

From the above obtained mAb clones, $22 \mathrm{G}$ for $V$. parahaemolyticus and $14 \mathrm{G}$ for nontoxic VT2 were selected for next $E$. coli expression and further investigation. The Zipbody with N-terminal SKIK peptide tag of clone $22 \mathrm{G}$ was expressed in E. coli Shuffle T7 Express. Since most of the target proteins were produced as inclusion bodies, refolding was tried. As a result, $82.8 \%$ of the refolded proteins was recovered as soluble fraction (Table 1). Finally, $27.4 \%$ was recovered as purified protein by His tag purification. Using this purified Zipbody as the first antibody, binding activity for the antigen was observed in ELISA (Figure 3). In the case of $14 \mathrm{G}$ clone for nontoxic VT2, Cys residues in constant regions which might be involved in intermolecular disulfide bonds were converted to Ser. In this study we constructed two mutants, (1) Lc $(C \rightarrow S), \mathrm{Hc}(C C \rightarrow S C)$ and $(2) \mathrm{Lc}(C \rightarrow S), \mathrm{Hc}(C C \rightarrow S S)$, then $\mathrm{Lc}$ and Hc were independently expressed in BL21 (DE3). As this also resulted in protein production in inclusion bodies, Lc and Hc were mixed and refolded as described above. ELISA showed enough 
binding activity to the antigen (Figure 4), implying expression in BL21 (DE3) and refolding the mixture of $\mathrm{Lc}$ and $\mathrm{Hc}$ would be effective for active rabbit $\mathrm{mAb}$ production.

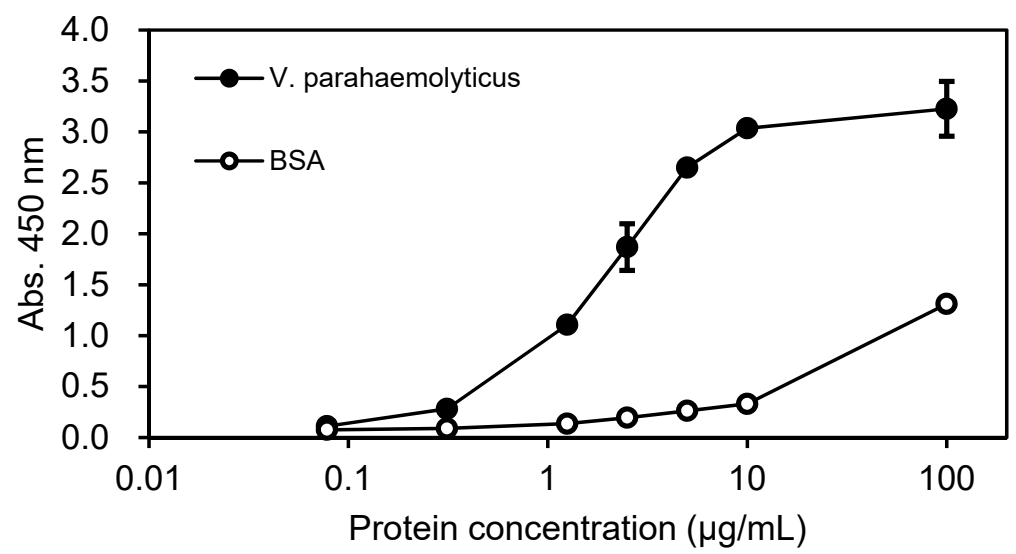

Figure 3. ELISA results of the refolded and purified Zipbody $22 \mathrm{G}$ clone for V. parahaemolyticus. Error bars indicate standard deviations.

Table 1. Recovery of refolding and purification of $22 \mathrm{G}$ clone expressed in E. coli Shuffle T7 Express.

\begin{tabular}{ccccc}
\hline & $\begin{array}{c}\text { Protein Concentration } \\
(\mathbf{m g} / \mathbf{m L})\end{array}$ & Total Volume $(\mathbf{m L})$ & $\begin{array}{c}\text { Amount of } \\
\text { Protein }(\mathbf{m g})\end{array}$ & $\begin{array}{c}\text { Recovery Ratio } \\
\mathbf{( \% )}\end{array}$ \\
\hline Solubilization by 6 & 1.62 & 0.95 & 1.54 & \\
M GuHCl & 0.98 & 1.3 & 1.28 & 82.8 \\
Refolding & 0.094 & 4.5 & 0.423 & 27.4 \\
His tag purification & & & \\
\hline
\end{tabular}

Inclusion bodies produced in $50 \mathrm{~mL}$ of LB medium were used. The solubilized amount of protein is regarded as $100 \%$ in recovery ratio.

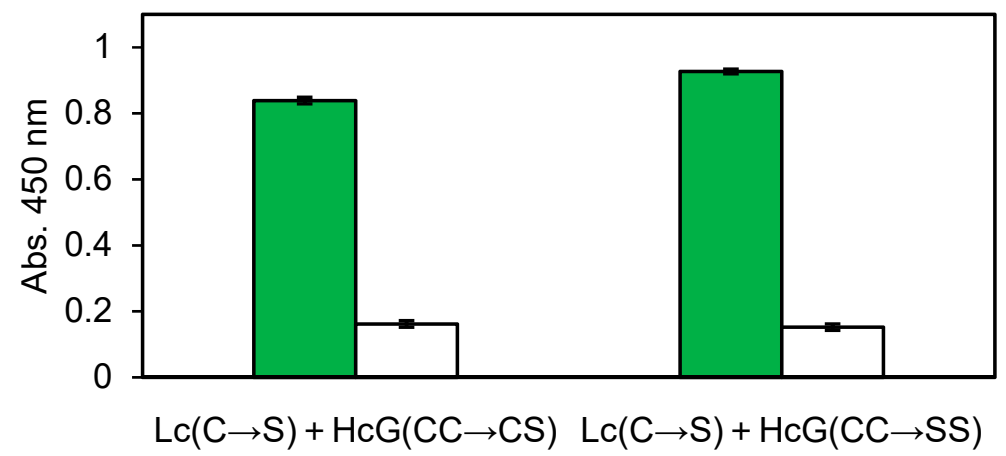

Figure 4. ELISA result of the refolded $14 \mathrm{G}$ mutated clones for nontoxic VT2. Green: Antigen, White: BSA. Error bars indicate standard deviations.

\subsection{Human mAbs Screening}

We attempted to obtain anti-influenza virus vaccine human mAbs from immortalized B cells by Ecobody technology. In order to select IgG-producing B cells, anti-human IgG antibody labeled with a fluorescent dye was used and B cells with highest fluorescence (about 30\%) were sorted by FACS. After removing cells nonspecifically bound to E. coli DH5 $\alpha$ dead cells, approximately $0.15 \%$ of the starting cells were collected by antigen coated magnetic beads. Of which, 21 cells were selected under microscope (Figure 5) and subjected to single-cell RT-PCR. Among these 15 pairs of Lc (kappa type) and Hc (gamma type) genes were obtained. Lambda type of Lc was also amplified from three cells. Therefore, a total of eighteen pairs of Lc and Hc were coexpressed in CFPS and 6-times diluted 
products were evaluated by ELISA. Figure 5 shows that all clones obtained in this screening, regardless of the types of Lc, had higher binding activity to the antigen.

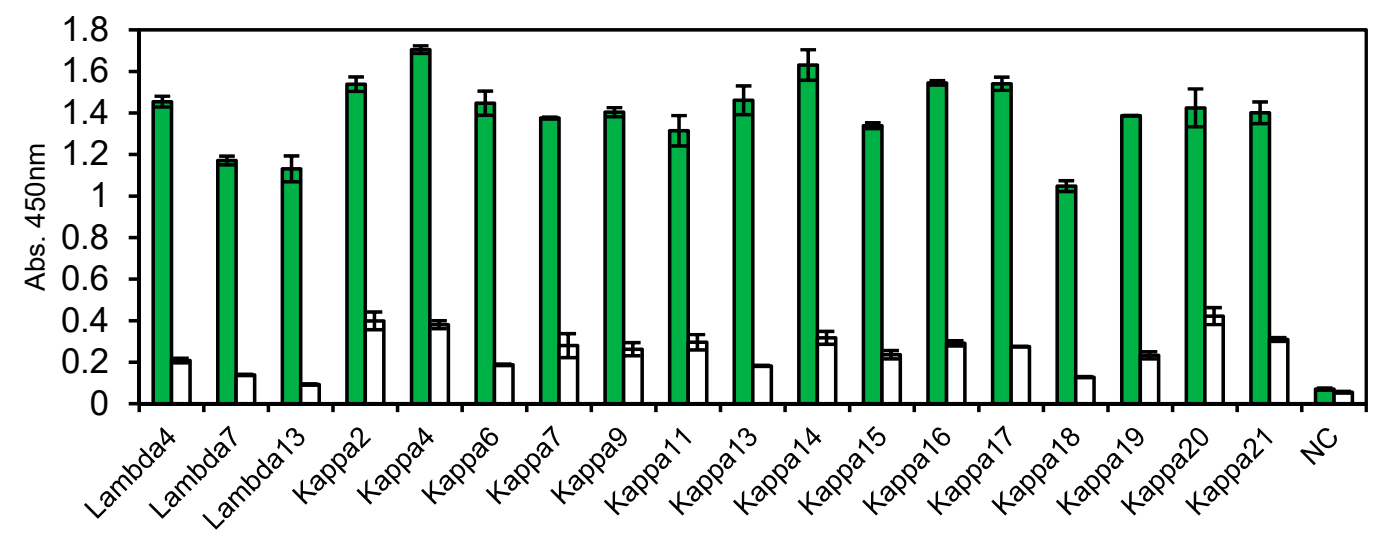

Figure 5. ELISA results of the cell-free products obtained from human B cells. Green: Influenza vaccine, White: BSA. Error bars indicate standard deviations.

No. 14 Zipbody was expressed in E. coli Shuffle T7 Express. Although most of the target proteins were confirmed in the insoluble fraction, they were also in the soluble fraction (data not shown). Therefore, we tried His tag purification from the soluble proteins and ELISA was conducted against individual influenza antigen, not vaccine mixture. As a result, this clone had reactivity to all (Figure 6). From this result, it was considered that No. 14 clone could recognize the common site of each influenza HA antigen.

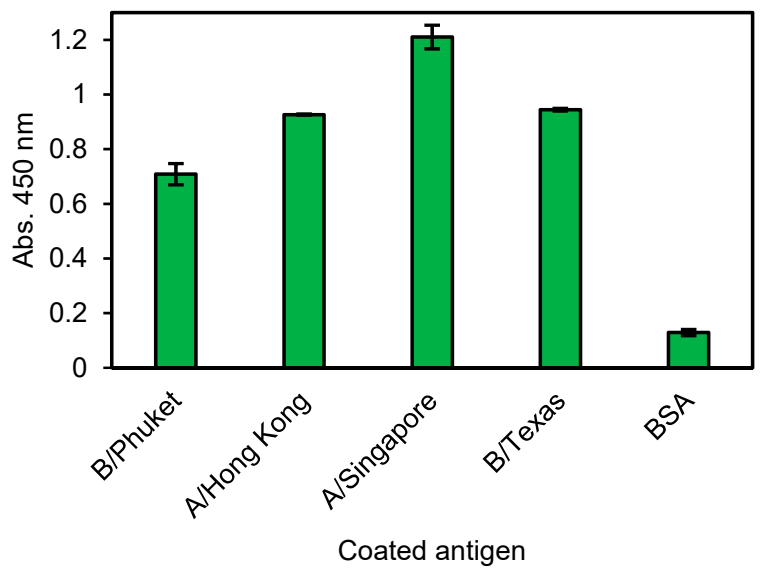

Figure 6. ELISA result of the E. coli expressed and refolded human No. 14 G Zipbody. Each antigen was coated on ELISA plate and $10 \mathrm{ng} / \mu \mathrm{L}$ of His tag purified Zipbody was used as the primary antibody. Error bars indicate standard deviations.

\section{Discussion}

Rapid discovery of mAbs which have high specificity and affinity to the antigens is important for accelerating life science research and industry. Here, we reported "Ecobody technology", allowing rapid screening of $\mathrm{mAbs}$ from single $\mathrm{B}$ cells of animals.

Using the immunized rabbits and immortalized human B cells, we demonstrated that it was possible to complete the process from isolation of $\mathrm{B}$ cells to $\mathrm{mAb}$ evaluation by manual operation in just two normal working days. The obtained $\mathrm{mAb}$ clones were produced as Zipbody proteins with an SKIK tag in CFPS and had binding activity to relevant antigens (Figures 2 and 5). All of the clones had binding activities to the target antigens. While pathogenic bacteria and protein were used as the antigen in this work, a rapid mAb screening by Ecobody technology will be available for challenging 
antigens like small chemicals and membrane proteins because B cells expressing mAbs against such antigens can be isolated by the same strategy with magnetic beads or FACS. In addition, as all the processes are carried out in tubes with only simple pipetting operations, Ecobody technology would be automated. This is a distinct advantage over other single B cell methods using animal cells, in which transfection and culturing of cells are necessary. We believe a rapid $\mathrm{mAb}$ screening would have great benefit for accelerating the mAb industry. In this study, most of the processes were performed with manual operations, and single B cell selection using microscopy was laborious, but the system could become more efficient by replacing manual operations to machine mediated processes.

Two rabbit mAb clones (22 G for V. parahaemolyticus and $14 \mathrm{G}$ for nontoxic VT2) and human $\mathrm{mAb}$ (No. 14 for influenza virus vaccine) with high ELISA signals were expressed in E. coli. Consistent with our previous study about the SKIK peptide tag [16], most of the target proteins were produced in insoluble fraction (data not shown). Therefore, we tried refolding the insoluble Zipbody by the method reported for $\mathrm{scFv}$, and successfully recovered $>80 \%$ of the insoluble proteins in a soluble form without optimization of the refolding process. His-tag purification of the refolded protein yielded about $8.5 \mathrm{mg}$ of purified $22 \mathrm{G}$ Zipbody from $1 \mathrm{~L}$ of LB medium (Table 1). The refolded and purified Zipbody had Hc-Lc association and the binding activity was sufficiently high (KD $=469 \mathrm{pM}$, data not shown) when compared with that of natural rabbit mAbs, which have KD values of a few hundred pM [17]. Interestingly two mutants in which particular Cys residues were removed also showed the ELISA signals after refolding (Figure 4), indicating Lc and Hc might be associated with LZ interaction. The molecular structure and stability of the refolded $\mathrm{mAbs}$, and the versatility of this method to obtain other $\mathrm{mAb}$ clones must be investigated, but we expect that rapid screening of mAbs by Ecobody technology coupled with E. coli expression has the potential to provide low cost $\mathrm{mAb}$ reagents applicable for diagnostics or research uses.

In conclusion, we adopted two techniques, Zipbody and the N-terminal SKIK peptide tag, and succeeded in developing a mAb screening system, Ecobody technology, allowing rapid generation of mAbs derived from single B cells.

\section{Conclusions}

Ecobody technology will be beneficial for rapid rabbit and human mAb screening.

Author Contributions: T.O.-K. and H.N.; Data curation, T.O.-K., T.K. and H.N.; Investigation, T.O.-K., S.M., Y.U., and S.N.; Methodology, T.O.-K., S.M., Y.U. and S.N.; Validation, T.O.-K., S.M., Y.U. and S.N.; Writing-original draft, T.O.-K. and H.N.

Funding: This research was funded by the 'Technological Development Project for Food Safety and Security' under Knowledge Hub AICHI.

Acknowledgments: We thank Shotaro Kubo (Nagoya University) and Yasuhiro Koide (Knowledge Hub AICHI project) for animal experiments and preparation of nontoxic VT2, respectively. The influenza HA vaccine used in this study was kindly supplied from The BIKEN Group (Osaka, Japan).

Conflicts of Interest: T.O.-K. and H.N. are the founder of iBody Inc. The company had no role in the design, execution, interpretation, or writing of the study. The other authors declare no conflict of interest.

\section{References}

1. Tiller, T. Single B cell antibody technologies. New Biotechnol. 2011, 28, 453-457. [CrossRef] [PubMed]

2. Kurosawa, N.; Yoshioka, M.; Fujimoto, R.; Yamagishi, F.; Isobe, M. Rapid production of antigen-specific monoclonal antibodies from a variety of animals. BMC Biol. 2012, 10, 80. [CrossRef] [PubMed]

3. Seeber, S.; Ros, F.; Thorey, I.; Tiefenthaler, G.; Kaluza, K.; Lifke, V.; Fischer, J.A.; Klostermann, S.; Endl, J.; Kopetzki, E.; et al. A robust high throughput platform to generate functional recombinant monoclonal antibodies using rabbit B cells from peripheral blood. PLoS ONE 2014, 9, e86184. [CrossRef] [PubMed]

4. Starkie, D.O.; Compson, J.E.; Rapecki, S.; Lightwood, D.J. Generation of Recombinant Monoclonal Antibodies from Immunised Mice and Rabbits via Flow Cytometry and Sorting of Antigen-Specific IgG+ Memory B Cells. PLoS ONE 2016, 11, e0152282. [CrossRef] [PubMed] 
5. Cox, K.S.; Tang, A.; Chen, Z.; Horton, M.S.; Yan, H.; Wang, X.M.; Dubey, S.A.; DiStefano, D.J.; Ettenger, A.; Fong, R.H.; et al. Rapid isolation of dengue-neutralizing antibodies from single cell-sorted human antigen-specific memory B-cell cultures. MAbs 2016, 8, 129-140. [CrossRef] [PubMed]

6. Ohashi, H.; Kanamori, T.; Shimizu, Y.; Ueda, T. A highly controllable reconstituted cell-free system-A breakthrough in protein synthesis research. Curr. Pharm. Biotechnol. 2010, 11, 267-271. [CrossRef] [PubMed]

7. Carlson, E.D.; Gan, R.; Hodgman, C.E.; Jewett, M.C. Cell-free protein synthesis: Applications come of age. Biotechnol. Adv. 2012, 30, 1185-1194. [CrossRef] [PubMed]

8. Zemella, A.; Thoring, L.; Hoffmeister, C.; Kubick, S. Cell-Free Protein Synthesis: Pros and Cons of Prokaryotic and Eukaryotic Systems. Chembiochem. 2015, 16, 2420-2431. [CrossRef] [PubMed]

9. Jiang, X.; Suzuki, H.; Hanai, Y.; Wada, F.; Hitomi, K.; Yamane, T.; Nakano, H. A novel strategy for generation of monoclonal antibodies from single B cells using rt-PCR technique and in vitro expression. Biotechnol. Prog. 2006, 22, 979-988. [CrossRef] [PubMed]

10. Sabrina, Y.; Ali, M.; Nakano, H. In vitro generation of anti-hepatitis B monoclonal antibodies from a single plasma cell using single-cell RT-PCR and cell-free protein synthesis. J. Biosci. Bioeng. 2010, 109, 75-82. [CrossRef] [PubMed]

11. Ojima-Kato, T.; Hashimura, D.; Kojima, T.; Minabe, S.; Nakano, H. In vitro generation of rabbit anti-Listeria monocytogenes monoclonal antibody using single cell based RT-PCR linked cell-free expression systems. J. Immunol. Methods 2015, 427, 58-65. [CrossRef] [PubMed]

12. Arai, H.; Glabe, C.; Luecke, H. Crystal structure of a conformation-dependent rabbit IgG Fab specific for amyloid prefibrillar oligomers. Biochim. Biophys. Acta 2012, 1820, 1908-1914. [CrossRef] [PubMed]

13. Groff, D.; Armstrong, S.; Rivers, P.J.; Zhang, J.; Yang, J.; Green, E.; Rozzelle, J.; Liang, S.; Kittle, J.D.; Steiner, A.R.; et al. Engineering toward a bacterial 'endoplasmic reticulum' for the rapid expression of immunoglobulin proteins. Mabs 2014, 6, 671-678. [CrossRef] [PubMed]

14. Cai, Q.; Hanson, J.A.; Steiner, A.R.; Tran, C.; Masikat, M.R.; Chen, R.; Zawada, J.F.; Sato, A.K.; Hallam, T.J.; Yin, G. A simplified and robust protocol for immunoglobulin expression in Escherichia coli cell-free protein synthesis systems. Biotechnol. Prog. 2015, 31, 823-831. [CrossRef] [PubMed]

15. Ojima-Kato, T.; Fukui, K.; Yamamoto, H.; Hashimura, D.; Miyake, S.; Hirakawa, Y.; Yamasaki, T.; Kojima, T.; Nakano, H. 'Zipbody' leucine zipper-fused Fab in E. coli in vitro and in vivo expression systems. Protein Eng. Des. Sel. 2016, 29, 149-157. [CrossRef] [PubMed]

16. Ojima-Kato, T.; Nagai, S.; Nakano, H. N-terminal SKIK peptide tag markedly improves expression of difficult-to-express proteins in Escherichia coli and Saccharomyces cerevisiae. J. Biosci. Bioeng. 2017, 123, 540-546. [CrossRef] [PubMed]

17. Ojima-Kato, T.; Nagai, S.; Nakano, H. Ecobody technology: Rapid monoclonal antibody screening method from single B cells using cell-free protein synthesis for antigen-binding fragment formation. Sci. Rep. 2017, 7, 13979. [CrossRef] [PubMed]

18. He, X.; McMahon, S.; Skinner, C.; Merrill, P.; Scotcher, M.C.; Stanker, L.H. Development and characterization of monoclonal antibodies against Shiga toxin 2 and their application for toxin detection in milk. J. Immunol. Methods 2013, 389, 18-28. [CrossRef] [PubMed]

19. Iwakawa, M.; Goto, M.; Noda, S.; Sagara, M.; Yamada, S.; Yamamoto, N.; Kawakami, Y.; Matsui, Y.; Miyazawa, Y.; Yamazaki, H.; et al. DNA repair capacity measured by high throughput alkaline comet assays in EBV-transformed cell lines and peripheral blood cells from cancer patients and healthy volunteers. Mutat. Res. 2005, 588, 1-6. [CrossRef] [PubMed]

20. Tsumoto, K.; Shinoki, K.; Kondo, H.; Uchikawa, M.; Juji, T.; Kumagai, I. Highly efficient recovery of functional single-chain Fv fragments from inclusion bodies overexpressed in Escherichia coli by controlled introduction of oxidizing reagent-Application to a human single-chain Fv fragment. J. Immunol. Methods 1998, 219, 119-129. [CrossRef]

(C) 2018 by the authors. Licensee MDPI, Basel, Switzerland. This article is an open access article distributed under the terms and conditions of the Creative Commons Attribution (CC BY) license (http:/ / creativecommons.org/licenses/by/4.0/). 